\title{
Safety and Efficacy of Vascular Access Devices in Patients Who Inject Drugs: A Quantitative Descriptive Review
}

Leo Andrew Almerol and Val Wortley Bedfordshire Hospitals NHS Foundation Trust

Article Information

DOI:

https://doi.org/10.38192/1.6.3.pnauk.wcc20. ab2

Epub: 11.10 .2020

\section{Abstract presented at Philippine Nurses UK World Café Convention 24 October 2020}

Keywords: vascular access devices,

Background: Persons who inject drugs (PWID) have difficult venous access with the perception of damage to veins. In the UK $0.4 \%$ of the population injects illicit substances $(1,2)$. These patients tend to have complex needs when they present to the hospital. This review aims to determine the prevalence as well as the safety and efficacy of vascular access devices (VAD) inserted by the vascular access team in a county hospital in the East of England.

Methods: This quantitative descriptive review looked into the database from 2008 until August 2020. Devices inserted in adult patients who are assessed as IV drug users were included in the review.

Results: Out of the total 6581 devices inserted in the study period, only $83(1 \%)$ vascular access devices were identified to have been inserted in the above population (totalling 1,369 catheter days, average 16 inpatient days, deviation $s=25.68$ ). The devices were; 52 Peripherally inserted central cannulas (PICCS), 28 midlines, 2 ultrasound-guided peripheral intravenous catheters, and 1 Leaderflex ${ }^{\circledR}$ cannula. $^{2}$

There were $9(10 \%)$ device insertions that failed where an intended device had to be replaced with a different device. The failed insertions were: 6 PICCs failed on insertion which had to be rewired to a midline, 2 ultrasound-guided cannulas which had to be rewired to a midline, and 1 failed both a midline and a PICC and ended up having a Leaderflex ${ }^{\circledR}$ cannula via guidewire exchange method.

The most common reason for device insertion was for use with intravenous antibiotic treatment at 44 (53\%), 27 (33\%) were inserted for venous access, $6(7 \%)$ were required for contrast injection with CT Scan, 4 (4\%) for MRI and 2 (2\%) for total parenteral nutrition.

Out of the 56 subjects, 33 were known to have injected drugs, 18 had previous IV drug use, 3 were currently injecting drugs, and 2 were smoking Heroin. Three subjects were suspected to have used the line.

The incidence of Hepatitis C were 12 (21\%) and 1 (2\%) with Hepatitis A.

The outcomes of the devices were: 44 (53\%) reached the end of their treatment, 14 (17\%) were discharged home after line removal, 10 (12\%) had to be rewired, 5 (6\%) were self or accidentally removed, 4 (5\%) was removed for suspected line infection, 1 (1\%) had to be removed because of occlusion, 1 (1\%) thrombosis, $1(1 \%)$ death which is not related to IVDU cause, and 1 (1\%) ex-IVDU was discharged home to have 4-6 weeks of antibiotics with the outpatient antibiotic therapy service.

Conclusions: PWIDs required multidisciplinary care when they become an in-patient. Risk assessment should be included on admission to determine appropriate interventions. Suitable VAD selection for the contemplated treatment and consideration of the use of ultrasound during placement improves success (3). Policy and guidelines should be established to prevent abuse (4), minimize complications and improve patient safety within this population (5).

Funding: Not Applicable

Ethics: Not Applicable

Declaration of Interest: Nothing to disclose

References:

1. NICE. Public Health Guidance 18 - Needle and Syringe Programmes, London: NICE, February 2009. 
2. Health Protection Agency. Shooting up. Infections among injecting drug users in the UK October 2008 (updated October 2009).

3. Sou, Vanno et al. "A clinical pathway for the management of difficult venous access." BMC nursing vol. 16 64. 17 Nov. 2017, doi:10.1186/s12912-017-0261-z

4. Ho J, Archuleta S, Sulaiman Z, Fisher D. Safe and successful treatment of intravenous drug users with a peripherally inserted central catheter in an outpatient parenteral antibiotic treatment service. J Antimicrob Chemother. 2010;65(12):2641-2644.

doi:10.1093/jac/dkq355

5. Glauser et Al 2016, Hospital Policies Put the Lives of People Who Inject Drugs at Risk, say experts https://healthydebate.ca/2016/07/topic/harm-reductionhospitals-injection-opioids 